\title{
OÚRICUR'
}

\section{ALTERAÇÕES CLIMÁTICAS, CONTRIBUTOS PARA AS PERCEÇÕES PÚBLICAS}

\author{
Carmen Diego GONÇALVES ${ }^{1 *}$; Orfeu BERTOLAMI ${ }^{2}$ \\ ${ }^{1}$ Doutora em Sociologia, Investigadora Colaboradora HH-Uma-CIERL (Portugal). \\ *Autor correspondente. E-mail: cdiegogoncalves@gmail.com \\ ${ }^{2}$ Professor Doutor, Departamento de Física e Astronomia, FCUP (Portugal). \\ E-mail: orfeu.bertolami@fc.up.pt \\ Recebido: 18.02.2021 Aceito: 01.06.2021
}

\begin{abstract}
Resumo: Neste artigo, de divulgação científica, e reflexivo, abordamos o tema do clima, resultado de um delicado equilíbrio entre agentes variados, que ao ser quebrado induz mudanças climáticas, causadas por processos naturais da própria Terra, ou por forças externas, e mais recentemente resultado da ação humana com repercussões no observado aquecimento global, bem como no aumento de fenômenos cujo impacto social provocam os denominados riscos ou desastres naturais. A importância da interdisciplinaridade é salientada ao longo do trabalho, para um melhor entendimento das alterações climáticas; das suas causas e efeitos, do seu impacto na natureza e na sociedade, enquadrada no paradigma do desenvolvimento sustentável, em tempos de emergência de uma nova era geológica denominada de Antropoceno, onde o risco decorrente do impacto do comportamento humano no Planeta (risco antrópico) é preponderantemente negativo. A recolha de material para este trabalho foi de cariz bibliográfico e técnico, tendo também por base trabalho conjunto que tem vindo a ser desenvolvido pelos autores, e colegas, tanto no âmbito de publicações quanto no desenho de projectos de investigação, integrando as áreas da física e astronomia, sociologia e filosofia, aflorando, ainda, questões do âmbito da geologia. Considerando que o entendimento da multidimensionalidade deste objecto de reflexão está ancorado em dimensões culturais e comunicacionais, que permitem construções sociais de significados, e perceções, sobre as alterações climáticas, esperamos contribuir para repensar os pressupostos em que estão ancoradas as representações sociais, acionadas na interpretação da informação que é socialmente veiculada sobre as alterações climáticas e, nesse sentido, apelar à comunidade científica para a importância da divulgação tanto interpares quanto para públicos leigos, uma das dimensões do ethos científico.
\end{abstract}

Palavras-chave: alterações climáticas; comunicação da ciência; perceções públicas; desenvolvimento sustentável

\section{CLIMATE CHANGE, CONTRIBUTIONS TO PUBLIC PERCEPTIONS}

ABSTRACT: In this scientific dissemination, and reflexive, article, we address the theme of climate, the result of a delicate balance between various agents, which when broken induces climate changes, caused by natural processes of the Earth itself, or by external forces, and more recently the result of human action with repercussions in the observed global warming, as well as in the increase of phenomena whose social impact provoke the so-called risks or natural disasters. The importance of interdisciplinarity is highlighted throughout the work, for a better understanding of climate change; of its causes and effects, of its impact on nature and society, framed in the paradigm of sustainable development, in times of emergence of a new geological era called Anthropocene, where the risk arising from the impact of human behavior on the Planet (anthropic risk) it is overwhelmingly negative. The collection of material for this work was bibliographic and technical, also based on joint work that has been developed by the authors, and colleagues, both in the scope of publications and in the design of research projects, integrating the areas of physics and

Revista Ouricuri, Juazeiro, Bahia, v.11, n.1. p.080-102. jan./jul., 2021.

http://www.revistas.uneb.br/index.php/ouricuri | ISSN 2317-0131 
astronomy, sociology and philosophy, also addressing issues related to geology. Considering that the understanding of the multidimensionality of this reflexive object is anchored in cultural and communicational dimensions, that allow social constructions of meanings, and perceptions, about climate change, we hope to contribute to the rethinking of assumptions in which are anchored the social representations, triggered in the interpretation of the information that is socially conveyed about climate change and, in this sense, appeal to the scientific community for the importance of dissemination both to peers and to lay audiences, one of the dimensions of the scientific ethos.

Keywords: climate change; science communication; public perceptions; sustainable development.

\section{CAMBIO CLIMÁTICO, CONTRIBUCIONES A LAS PERCEPCIONES DEL PÚBLICO}

RESUMEN: En este artículo, de divulgación científica y reflexiva, abordamos el tema del clima, resultado de un delicado equilibrio entre agentes variados, que al romperse induce cambios climáticos, provocados por procesos naturales de la propia Tierra, o por fuerzas externas y más recientemente el resultado de la acción humana con repercusiones en el calentamiento global observado, así como en el aumento de fenómenos cuyo impacto social provocan los denominados riesgos o desastres naturales. La importancia de la interdisciplinariedad se destaca a lo largo del trabajo, para una mejor comprensión del cambio climático; de sus causas y efectos, de su impacto en la naturaleza y la sociedad, enmarcado en el paradigma del desarrollo sostenible, en tiempos de emergencia de una nueva era geológica denominada Antropoceno, donde el riesgo derivado del impacto del comportamiento humano en el Planeta (riesgo antrópico) es abrumadoramente negativo. La recopilación de material para este trabajo fue bibliográfica y técnica, también basada en el trabajo conjunto que ha sido desarrollado por los autores, y colegas, tanto en el ámbito de las publicaciones como en el diseño de proyectos de investigación, integrando las áreas de física y astronomía, sociología y filosofía, abordando también temas relacionados con la geología. Considerando que la comprensión de la multidimensionalidad de este objeto de reflexión se ancla en dimensiones culturales y comunicacionales, que permiten construcciones sociales de significados y percepciones sobre el cambio climático, esperamos contribuir a repensar los supuestos sobre los que se anclan las representaciones sociales, desencadenó en la interpretación la información que se transmite socialmente sobre el cambio climático y, en este sentido, apelar a la comunidad científica por la importancia de la divulgación tanto a pares como a públicos profanos, una de las dimensiones del ethos científico.

Palabras clave: cambio climático; comunicación científica; percepciones públicas; desenvolvimiento sustentable.

\section{INTRODUÇÃO}

Tendo como enquadramento as sociedades de risco, abordaremos o tema das alterações climáticas, decorrentes do predominantemente negativo impacto da acção do homem sobre o aquecimento global do Planeta, não dissociado de modelos de desenvolvimento econômico e subjacentes opções políticas, considerando a importância da comunicação científica para as perceções individuais e sociais sobre o tema, contribuindo para avaliações, decisões e comportamentos.

O conceito de "sociedade de risco" descreve sociedades onde o seu modelo de desenvolvimento tem conduzido a uma coexistência pouco pacífica da distribuição dos "males" e dos "bens" (Beck, 1992; Beck et al. 1997). A reflexividade social e institucional tem sido vista como 
a resposta àqueles modelos de desenvolvimento em que a ciência e a tecnologia procuram encontrar os seus caminhos num mundo de incerteza crescente.

Nas condições da última fase da modernidade, modernidade reflexiva ou tardia (Giddens, 1992; Beck, 1999), o futuro está constantemente a ser desenhado no presente através de meios de organização reflexiva de ambientes de conhecimento (Giddens, 1991), remetendo, assim, para a dimensão cultural da definição de risco.

Beck (1999) considera, até, difícil distinguir entre conceção de 'risco cultural', na concepção de Scott Lash, e o seu próprio conceito de 'sociedade de risco' considerando mesmo de grande validade o facto de Lash (2000) ter dado ênfase à radicalização do enquadramento cultural do risco através da teoria cultural e dos estudos culturais. Defende, mesmo, que a 'relação de definição' na idade dos riscos culturalmente definidos continua, necessariamente, a fazer sentido para o conceito de 'sociedade de risco'. Em seu entender, o que constitui o risco será a sua definição cultural e, consequentemente a perceção do mesmo. Nesta perspectiva, 'risco' e 'definição (pública) de risco' estão ligados, já que todo o risco depende de atribuição de sentido e significado, em suma, de perceções associadas à interiorização de representações sobre objectos, socialmente veiculadas.

Salienta-se, assim, a importância social das perceções sobre os riscos decorrentes das alterações climáticas, já que introduzem uma particular relação com um futuro desconhecido, provavelmente antecipado, e que pode nunca ser possível de calcular deterministicamente, com base, apenas, em extrapolações sobre ocorrências do passado (já que a memória frequentemente desempenha um papel muito importante nas perceções), numa calculada resposta sociocultural aos potenciais acontecimentos antecipados.

A génese da incorporação de matéria significante apelando à função sociocultural da memória, chama ao presente a história que se presume continuará no futuro (Moscovici et Hewstone, 1984). Como afirma Connerton (1993), o mundo do inteligível, definido em termos de experiência temporal, é um corpo organizado de expectativas baseadas na recordação. Neste sentido, as experiências do presente são sempre fundamentadas formas de conhecimento contextualizadas no passado que, desta forma, garantem a sua inteligibilidade. Antes de qualquer experiência, a nossa mente encontra-se já predisposta a inseri-la numa estrutura de contornos, de formas conhecidas e objectos já experimentados. Compreender um objecto, ou agir sobre ele, pressupõe a sua localização neste sistema de expectativas. Assim, a memória social, é histórica, mas transportada e actualizada no presente pelos indivíduos (Jodelet, 2001).

Ora, sendo o conhecimento sobre o clima, se bem que vasto, incompleto, e um ramo da ciência em permanente expansão e aperfeiçoamento os avanços no conhecimento necessitam de adequada comunicação social, que esclareça e permita categorizar, relativizar crenças e tomar decisões sobre riscos e comportamentos a adoptar (Diego Gonçalves, 2004), pois as diferentes categorias de perceções leigas estão ancoradas na organização dos sistemas simbólicos e edificam os mesmos. 
Por sua vez constituindo as alterações climáticas um exemplo de incerteza científica, cujos impactos sociais apelam à sociologia da ciência e do conhecimento, do risco e da comunicação, à interdisciplinaridade, torna necessária a inovação metodológica no desenho da investigação e sua disseminação para os diversos atores sociais; stakeholders ${ }^{1}$ e técnicos, líderes de opinião e políticos e público leigo, pois quando a ciência não é suficiente e a incerteza é grande, os riscos exigem medidas políticas de prevenção e precaução, prevenindo riscos conhecidos e evitando riscos desconhecidos. Contribuindo, a comunicação da ciência, para a capacitação dos cidadãos sobre decisões relacionadas com os riscos que consideram aceitáveis.

Segundo Beck (1992), a visibilidade do risco tem duas fases; a natureza do risco e as perceções públicas do mesmo. Os riscos decorrentes da acção humana estão a aumentar. E as nossas visões sobre os mesmos terão mudado? Não está, ainda, claro. Mas, uma coisa parece certa, a de que tanto a natureza dos riscos e as perceções públicas dos mesmos convergem, condicionam-se e intensificam-se mutuamente, e porque os riscos são sempre riscos em conhecimento, dependem de uma avaliação sobre os mesmos para a sua gestão.

Um dos aspectos da gestão do risco é aquele que se centra na agência dos actores. Em muitas situações, as pessoas mostram uma considerável resistência em lidar com o risco, adoptando, por vezes, uma atitude de cepticismo, ou mesmo de rejeição; preocupando-se com a avaliação dos riscos sobre os quais têm, pelo menos alguma, informação, contra outros riscos, presentes, embora, na sua vida quotidiana, mas que são menos publicitados por parte das estruturas sociais. As pessoas, por um lado, mostram mais facilidade em lidar com um perigo que se conhece, que se sabe quando poderá ocorrer, e portanto oferece mais garantias de poder ser controlado, do que o inverso, que gera grandes níveis de insegurança e, por outro lado, demonstram-se avessas ao risco se a fasquia das perdas é alta e mostram-se propensas ao risco se, inversamente, os ganhos são grandes (Slovic, 2000).

Outro dos aspectos das preocupações públicas da gestão do risco é o de que em seu nome o controle possa ser reivindicado pelos governos ou outros corpos de poder sobre as populações. Ou, eventualmente, ser até explorado em função de interesses, económicos, nomeadamente, com base em argumentos de defesa do ambiente e dos interesses das populações (Diego Gonçalves, 2004). Neste sentido, tanto as definições de risco quanto as percepções sobre os mesmos, tanto podem ser consideradas ferramentas conceptuais hegemónicas que podem, numa determinada perspectiva, servir as estruturas de poder na sociedade, quanto podem servir para capacitar decisões públicas.

\footnotetext{
1 Stakeholder: (em português, parte interessada ou interveniente). A palavra "stakeholder" é usada para significar uma pessoa ou organização que tem interesse legítimo num projeto ou entidade. Ao discutir o processo de tomada de decisão para instituições - incluindo grandes corporações de negócios, agências governamentais e organizações sem fins lucrativos - o conceito inclui todos que têm interesse (ou "participação") naquilo que a entidade faz.
} 
Os estudos sobre risco têm, também, demonstrado a necessidade de que, no âmbito do princípio de precaução, se reflicta sobre as dinâmicas entre as dimensões do risco, da confiança, da participação e da necessidade de regulação e da responsabilidade (Wynne, 1996).

Os efeitos a médio e longo prazo das alterações climáticas justificam, assim, claramente a necessidade de interdisciplinaridade na compreensão e a divulgação científica sobre o tema, contribuindo para o esclarecimento e conhecimento do público em geral, o que em si mesmo, é um direito de cidadania, em Estados de Direito; conhecimento, esse, em cujos pressupostos se poderão tomar decisões colectivas e individuais na exigência de medidas que protejam a qualidade de vida dos cidadãos no Planeta, que é de todos. E, a divulgação científica impõe-se, sendo nesta dimensão, que o cientista executa uma das dimensões do seu ethos, definida por Merton (1985), a da comunicação da ciência prefigurando o papel cultural do cientista (Diego Gonçalves, 1996 a;b).

\section{ALTERAÇÕES CLIMÁTICAS, UM RISCO ANTRÓPICO}

Os termos: mudança do clima, mudança climática ou alteração climática referem-se à variação do clima à escala global, ou dos climas regionais da Terra ao longo do tempo. Estas variações dizem respeito a mudanças de temperatura, precipitação, nebulosidade e outros fenómenosclimáticos em relação às médias históricas. Para tanto, há causas naturais (internas à Terra no sistema planetário) que concorrem para as mudanças climáticas (escurecimento global; recuo dosglaciares desde 1850; ciclo solar, variação orbital; impacto de meteoritos; deriva dos continentes emovimentação de placas tectónicas; movimentos orogenéticos de formação de montanhas; mudanças de temperatura nas água dos oceanos; variação de intensidade dos ventos alísios; vulcanismo). Mas, o clima terrestre manifesta cada vez mais fenómenos extremos (como cheias, secas, granizo, tornados, furacões, etc.), os quais podem ter efeitos devastadores, a vários níveis:natural e humano, social, económico, político, geográfico, cultural - que se devem à "mudança climática" devida à atividade humana alterando a composição da atmosfera caracterizada pelo aumento inequívoco e continuado da temperatura média do sistema climático da Terra - denominado aquecimento global (Graedel and Crutzen, 1995).

Nenhuma instituição científica de reputação nacional ou internacional mantém uma opinião dissidente. Segundo o "Painel Intergovernamental sobre Mudanças Climáticas" (IPCC na sigla em inglês), mudança climática é uma variação a longo prazo, estatisticamente significativa num parâmetro médio climático (como temperatura, precipitação ou ventos), ou na sua variabilidade, durante um período de tempo que pode variar de décadas a milhões de anos. A Convenção-Quadro das Nações Unidas sobre a Mudança de Clima (CQNUMC) faz uma distinção entre a "variabilidade climática" atribuída a causas naturais e a "variabilidade climática" devida à actividade humana alterando a composição da atmosfera. No contexto da CQNUMC, as alterações climáticas são definidas como uma mudança do clima atribuída, direta ou indiretamente, à atividade humana 
(antrópica), que altera a composição da atmosfera e que associada à variabilidade natural do clima é observada por longos períodos de tempo.

\section{Aquecimento Global}

Esta área do conhecimento começou a desenvolver-se no início do século XIX, com os estudos do matemático e físico francês Jean-Baptiste Joseph Fourier sobre a decomposição de funções periódicas em séries trigonométricas convergentes chamadas séries de Fourier e a sua aplicação aos problemas da condução do calor. Os seus cálculos mostravam que a Terra devia ser mais fria do que é, considerando a quantidade de calor recebida do Sol. Fourier não descobriu a causa para tal, mas imaginou que os gases da atmosfera poderiam reter parte do calor recebido, funcionando como uma estufa - e por isso, de um modo geral, se atribui a Fourier a descoberta do efeito de estufa. E, o que é o efeito de estufa? É a retenção de radiação infravermelha por gases na atmosfera. É um processo natural, do qual dependem a estabilidade do clima do planeta e a moderação das suas variações extremas.

Níveis estáveis de certos gases atmosféricos, os chamados gases efeito de estufa, são fundamentais para a preservação da vida na Terra, contudo, o homem tem vindo a produzir uma quantidade considerável de gases poluentes através das suas actividades que contribuem para desestabilizar o equilíbrio natural de que depende a estabilidade do clima e a moderação das suas variações. Entre eles destacam-se o gás carbónico que é o principal gás efeito de estufa de origem humana, com outros em menores proporções, como o metano, o óxido nitroso e os perfluorcarbonetos ${ }^{2}$.

As principais causas diretas do aumento dos níveis de gases poluentes na atmosfera decorrem de processos industriais e agro-pecuários, como a queima de combustíveis fósseis (carvão, petróleo e gás em veículos, nas fábricas, e nas centrais elétricas), a desflorestação (na medida em que menos vegetação fica disponível para absorver o $\mathrm{CO}_{2}$ ), aterros inadequados de resíduos orgânicos e o desperdício de alimentos, o metano libertado nos aterros sanitários e na atividade agropecuária (nomeadamente no processo digestivo do gado bovino), o óxido nitroso libertado pelos fertilizantes, e os gases empregues em processos de refrigeração. Mas, de todos os gases presentes na atmosfera, devido à sua concentração, o principal responsável pelo aquecimento global é o dióxido de carbono $\left(\mathrm{CO}_{2}\right)$.

A elevação da concentração desses gases na atmosfera desencadeia reações à escala planetária, retendo calor e modificando virtualmente todos os sistemas físicos, químicos e biológicos da Terra incluindo o clima. As reações químicas são aceleradas com a elevação das temperaturas. Grande parte dos seres vivos não regula a sua temperatura corpórea e mais ou menos acompanha

\footnotetext{
${ }^{2}$ Nome genérico que se dá ao grupo de compostos orgânicos constituídos exclusivamente por átomos de carbono e flúor.
}

Revista Ouricuri, Juazeiro, Bahia, v.11, n.1. p.080-102. jan./jul., 2021. 
os níveis do ambiente. Os gases estufa do ar impregnam os oceanos e acentuam a sua acidez, além de contribuírem para uma maior desoxigenação. O aumento da temperatura interfere no ciclo das chuvas e na quantidade de água a que temos acesso; faz os gelos derreterem modificando ecossistemas e reduzindo o albedo (ou coeficiente de reflexão) terrestre; faz o oceano aquecer e aumentar de volume; altera as correntes marinhas e a estratificação da coluna de água; derrete os solos congelados; aumenta o nível de humidade no ar e reduz a humidade do solo; modifica balanços energéticos e ciclos bioquímicos; intensifica tempestades e desastres ambientais, e introduz uma infinita série de outras modificações nos sistemas da Terra, que reagem entre si amplificando os efeitos e desencadeando novas causas.

Mudanças progressivas no ambiente físico introduzem, assim, desequilíbrios progressivos, na biologia e na relação entre as espécies, o que se reproduz em cascata na Terra. Se as mudanças continuarem a ser tão rápidas como as que estão a acontecer, e se se aprofundarem significativamente, como está previsto por cientistas: algumas cidades costeiras poderão ficar inundadas; algumas zonas com chuva e queda de neve abundantes poderão tornar-se mais quentes e secas; os leitos de alguns rios e lagos poderão secar; o número de secas poderá aumentar, prejudicando as colheitas; as reservas de água potável para consumo, higiene, agricultura e produção de alimentos poderão diminuir; poderá ocorrer a extinção de muitas espécies animais e vegetais; certos fenómenos climáticos extremos, como furacões, tornados e outras tempestades, que sejam causados por alterações na temperatura e no mecanismo de evaporação da água, poderão tornar-se mais frequentes.

A grande maioria dos seres não poderá evoluir modificando a sua biologia a tempo de acompanhar a mudança dos sistemas físicos onde vive, terá sérios problemas para encontrar alimento e se reproduzir, ficará mais propensa a doenças e malformações, e o inevitável poderá vir a ser uma extinção em massa. Pode-se facilmente imaginar a repercussão catastrófica de um evento desta natureza e com tais consequências sobre a espécie humana e as sociedades, já que da natureza o homem depende a todos os níveis. A nível social, a repercussão já é visível na economia, na política, na saúde, no abastecimento e na segurança social, entre outras áreas.

Depois de Fourier vieram outros cientistas, como John Tyndall e Svante Arrhenius, que delimitaram melhor o campo, mas foi Guy Stewart Callendar o primeiro, na década de 1930, a medir objetivamente um aumento real na temperatura média da Terra ocorrido nos cinquenta anos anteriores. Mesmo com esses dados, a sua teoria recebeu pouco crédito, como tinha acontecido já com os seus precursores. Era um campo praticamente inexplorado pela ciência, os dados eram escassos e havia muita incerteza relativamente à generalidade das observações. $E$, assim, este assunto permaneceu em letargia até aos anos 50 do século passado, altura em que muitos dados relacionados com o clima foram coligidos em observações e experiências militares. Como resultado começava, então, a pensar-se seriamente que o aumento da concentração do gás carbónico na 
atmosfera poderia tornar-se um perigo no futuro, nomeadamente, com o crescimento da produção industrial.

Em 1957, o climatologista Charles Keeling ajudou a implantar um sistema de monitorização da concentração dos gases atmosféricos em todo o planeta. As leituras diárias da concentração de $\mathrm{CO}_{2}$ tiveram início no ano seguinte, e a partir de 1964 estas passaram a ser feitas sem interrupção até aos dias de hoje. A representação gráfica destes resultados é conhecida como Curva de Keeling. Os registos de Keeling sobre a concentração de dióxido de carbono atmosférico despertaram o alerta mundial para a contribuição antropogénica do efeito de estufa e do aquecimento global.

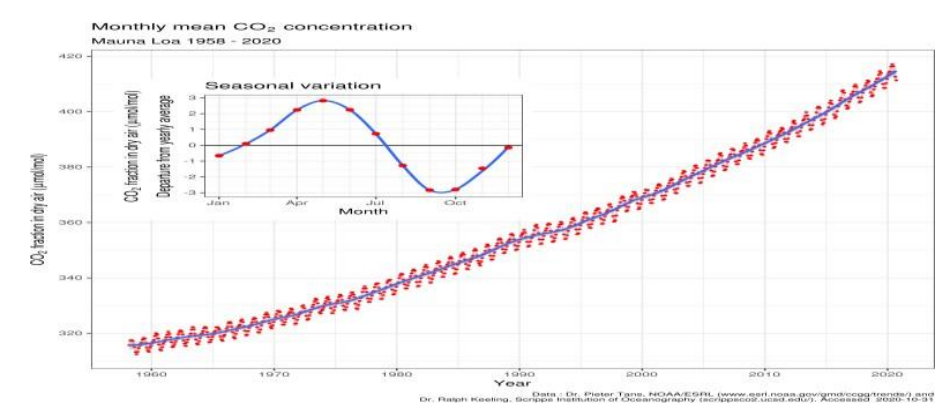

Gráfico 1 - Concentração atmosférica de $\mathrm{CO}_{2}$ ) desde 1959 até 2020.

(Fonte: Wikipedia, Keeling Curve)

Keeling começou e supervisionou o programa de monitorização de concentração de dióxido de carbono na atmosfera, até à data da sua morte, em 2005. O gráfico representa a acumulação de dióxido de carbono na atmosfera terrestre com base nas continuadas medidas feitas no Observatório de Mauna Loa, na ilha do Hawaii, desde 1958 até aos nossos dias. A curva continua a subir, registando recorde de dióxido de carbono.

Entre os factores que explicariam o caráter ascendente da curva estão a emissão de $\mathrm{CO}_{2}$ pela queima de combustíveis, a desflorestação, e o facto de que o oceano não é capaz de absorver

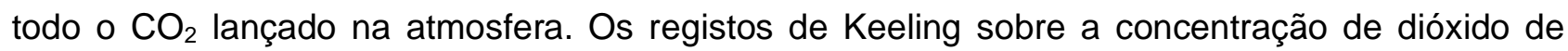
carbono atmosférico despertaram o alerta mundial para a contribuição antropogénica do efeito de estufa e do aquecimento global, que caracterizam a nova era geológica - o Antropoceno ${ }^{3}$ - existindo já registos estratigráficos suficiente que permitem à Sociedade Internacional de Estratigrafia esta classificação.

\footnotetext{
${ }^{3}$ Paul Crutzen, pioneiro em química atmosférica, vencedor do Nobel da Química de 1995, foi um dos cientistas que popularizou o conceito de "Antropoceno".
} 


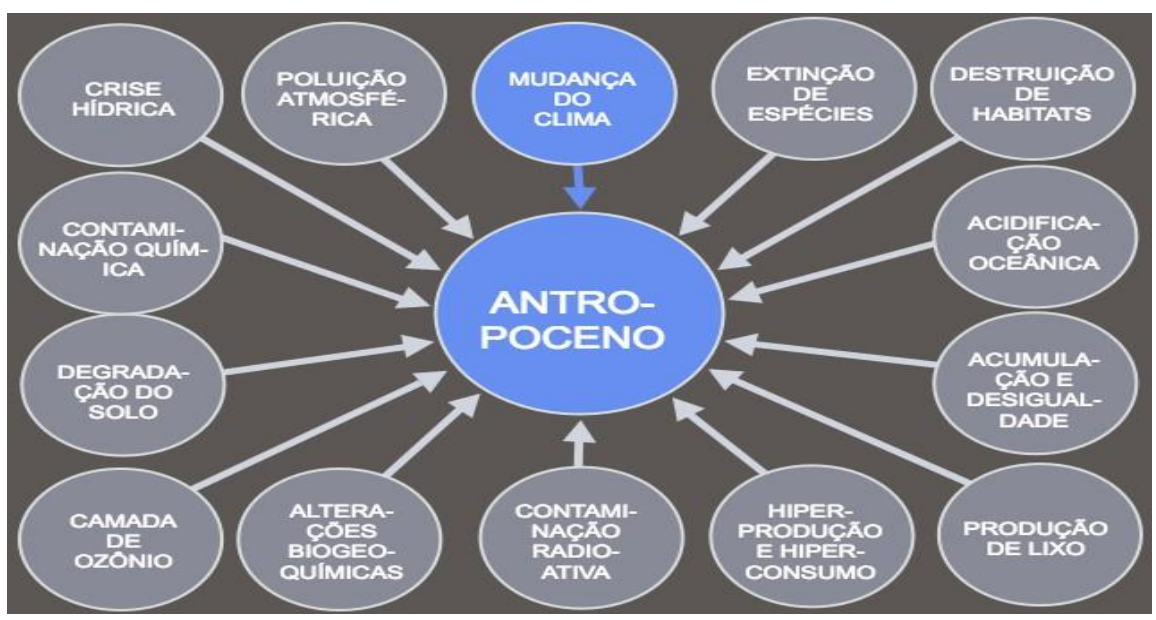

Figura 1 - O que você faria se soubesse o que eu sei?: O colapso (in)evitável e o Antropoceno (Fonte: oquevocefariasesoubesse.blogspot.com)

Este é, sinteticamente, o conhecimento atual sobre os efeitos das mudanças climáticas sobre a natureza, o homem, e as comunidades sociais. A compreensão teórica para tudo isso que assenta no produto da elevação da concentração dos gases efeito de estufa, sendo o homem o grande responsável por essa elevação e por um consequente potencial desarranjo ambiental a tal nível que ameaça a sua própria sobrevivência, demorou até ser aceite, e a certeza factual demoraria ainda mais a consolidar-se.

Não é provável que qualquer área da sociedade ou qualquer região do planeta venha a ser poupada a significativas, múltiplas e crescentes dificuldades, se as tendências nas alterações climáticas permanecerem inalteradas. E, a distribuição dos impactos será certamente bem desigual no Planeta, com maior impacto em regiões e contextos sócio geográficos mais vulneráveis, acentuando, e criando novas desigualdades sociais. Pois riscos democráticos não existem. O que existe são riscos transversais a toda a população, e situações contingentes que poderão permitir maiores danos, ou até mesmo danos não expectáveis, contudo as condições de vulnerabilidade populacional demonstram sempre que as populações e as comunidades que ficam mais expostas a riscos são as que à partida já têm níveis estruturais de vulnerabilidade mais elevados e, assim, de forma geral e probabilística demonstrarão menos capacidade de resiliência (Diego Gonçalves, $2012 ; 2015)^{4}$.

\section{CONTRATO DIGITAL PARA RESTAURAÇÃO DO SISTEMA TERRA}

Enfrentamos, hoje, um cenário de múltiplos riscos decorrentes das alterações climáticas, que exige uma mudança de visão do mundo não só na ciência, quanto nos comportamentos políticos, económicos, culturais, sociais.

\footnotetext{
${ }^{4}$ Onde se evidencia o contributo de determinadas variáveis sociais tanto para a vulnerabilidade, quanto para a resiliência.
}

Revista Ouricuri, Juazeiro, Bahia, v.11, n.1. p.080-102. jan./jul., 2021. 
Uma mudança de paradigma ocorreu nos meados do século XX. O poder computacional aumentou quase que exponencialmente. É, hoje, possível mobilizar uma quantidade enorme de dados e observações. E essa mudança de paradigma continua a evoluir, com efeitos visíveis na produção científica. Há hoje modelos teóricos que já simulam proposta para a preservação do Sistema Terrestre, nomeadamente "Digital Contract for Earth System Restoration Mediated by a Planetary Boundary Exchange Unit" (Bertolami and Francisco, 2021a). Este modelo está fortemente ancorado num corpo sólido de evidências, mostrando que são as atividades humanas que estão a conduzir o Sistema Terrestre a um novo estado, normalmente referido Aquecimento do Planeta, onde a sua temperatura média é necessariamente maior do que a atual e este pode ter um impacto irreversível sobre os ecossistemas reguladores do planeta, sendo improvável que proporcione um futuro sustentável para a humanidade. É proposto um novo paradigma de governança para a gestão do Sistema Terrestre baseado em um contrato digital inspirado na tecnologia de cadeia de blocos ${ }^{5}$.

$\mathrm{E}$, as variáveis sociais não podem deixar de fazer parte dos modelos que procuram preservar o equilíbrio terrestre com enfoque na resiliência humana e dos sistemas económicos, de saúde, de trabalho, enfim, políticos (Gonçalves and Bertolami, 2020 a;b). Neste sentido, estão os autores a desenhar investigação interdisciplinar, considerando que a resiliência, em contexto, só poderá ser incrementada por via de uma cada vez maior disseminação social do conhecimento científico, para diversos atores sociais, contribuindo para percepções ancorados na compreensão de factores de conhecimento necessários e suficientes a decisões e comportamentos. E, a ciência e a incerteza científica - parte integrante do seu método - não devem ser usadas, para justificar insuficientes medidas políticas e económicas; causa de problemas sociais estruturais, que ficam a descoberto em momentos de emergência e crise.

E, na medida em que as alterações climáticas poderão desencadear desastres, tanto naturais, quanto de conhecimento, e culturais, quaisquer ações, que se pretendam efectivas, aos níveis público e social, dependerão, certamente, de colaborações interdisciplinares, e com diversos atores sociais.

\section{IPCC E OUTROS ATORES SOCIAIS}

Desde que foi criado, em 1988, o IPCC (Painel Intergovernamental sobre mudanças climáticas), sob a chancela da Organização Meteorológica Mundial e o Programa das Nações Unidas para o Meio Ambiente, que se passou a publicar a partir de 1990 grandes relatórios periódicos, onde é apresentado o conhecimento de ponta sobre o aquecimento. Desde então os estudos não deixaram de se multiplicar, sendo um dos temas mais investigados atualmente, e a tendência é o crescente reforço do consenso científico que emergia já nos anos 1980. O IPCC estabeleceu-se como o principal porta-voz do consenso científico, que hoje ronda em torno de 97-98\%, e como a maior autoridade mundial sobre o aquecimento global, e as suas principais conclusões são as seguintes:

\footnotetext{
${ }^{5}$ Veja-se ainda: Bertolami e Francisco (2018a;b; 2019; 2021a;b); Barbosa et al., 2020; Steffen et al., 2018.
} 
o aquecimento da Terra é inequívoco; a influência humana sobre o clima é clara; a concentração de gases estufa na atmosfera está a aumentar; as temperaturas da superfície subiram em média $0,85^{\circ} \mathrm{C}$ (variação de 0,65 a $1,06^{\circ} \mathrm{C}$ ) de 1880 até 2012 ; cada uma das três últimas décadas superou a anterior nos níveis de temperatura; os oceanos estão a consumir mais de $90 \%$ da energia do sistema do clima e muito gás carbónico.

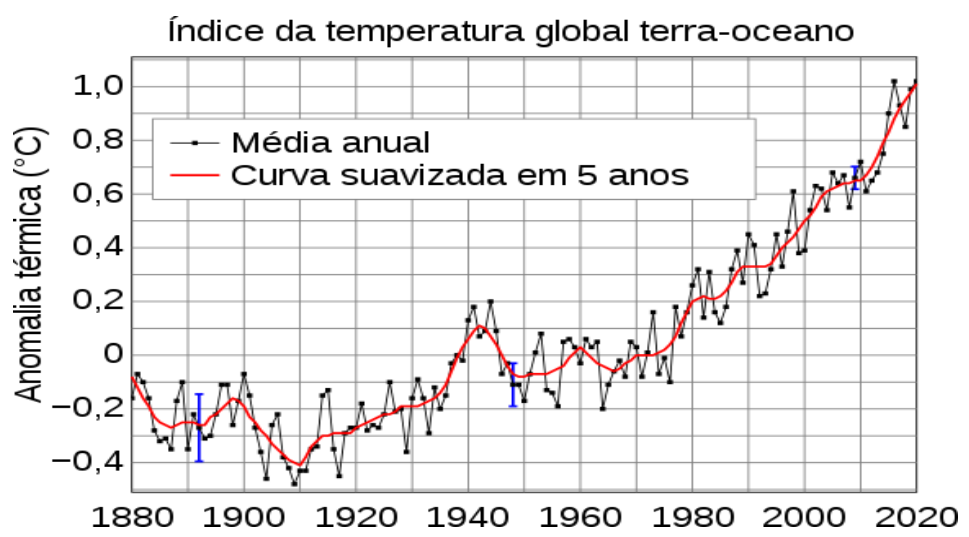

Gráfico 2 - A Terra está inequivocamente a aquecer. O gráfico mostra a evolução da temperatura média anual (fonte: Wikiwand).

No entanto, à medida que o oceano aquece, ele perde capacidade de absorver gás carbónico, o que pode acelerar os efeitos atmosféricos quando atingir a saturação. Os oceanos continuarão a acidificar-se e aquecer ao longo do século XXI e mesmo para além; o nível do mar aumentou em cerca de $19 \mathrm{~cm}$ entre 1901 e 2010 devido ao aumento térmico das águas; a elevação pode chegar a mais de $80 \mathrm{~cm}$ até 2100 ; sendo certo que o nível do mar vai continuar a subir depois de 2100; haverá impactos significativos sobre a natureza e a sociedade.

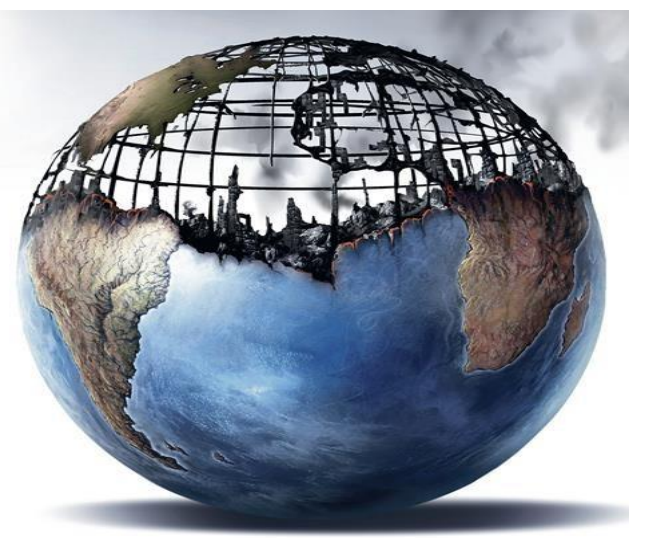

Figura 2, in Bertolami (2018b), Forumdemos, dezembro, 1, Utopia Ecológica, Utopias Europeias. (https://forumdemosnet.wordpress.com/2018/12/01/a-humanidade-no-antropoceno/).

Algumas consequências já se fazem notar no presente, como, por exemplo, um aumento na tendência de secas e enchentes. Se as emissões de gases continuarem altas e o aquecimento continuar em progressão, os impactos podem ser cumulativos e catastróficos. Estima-se que a temperatura média possa elevar-se a $4,8^{\circ} \mathrm{C}$ até 2100 . Na década de 1990 , quando os cientistas

Revista Ouricuri, Juazeiro, Bahia, v.11, n.1. p.080-102. jan./jul., 2021. 
falavam em aquecimento global focavam-se na temperatura anual média global e no aumento do nível do mar. O problema é que as pessoas não vivem à escala global, nem sentem temperaturas médias; sentem extremos - calor, chuva, seca - que as atingem em casa, ou num qualquer dia da semana, relativizou Richard Alley, docente da Universidade de Pensilvânia. "As gerações mais novas estão a crescer sem que haja qualquer normalidade", constatou Kristie Ebi, professor na Universidade de Washington, realçando que já são 406 os meses consecutivos em que o mundo está mais quente do que a média do século XX. Mais recentemente, o economista William Nordhaus, Prémio Nobel pela investigação sobre o impacto económico das alterações climáticas e outros problemas ambientais, disse à Associated Press que os seus cálculos apontam para prejuízos anuais para os EUA da ordem dos quatro mil milhões de dólares (3,5 mil milhões de euros) num cenário de aquecimento moderado de temperatura.

Em Davos, 2018, a partir do Banco Mundial, Georgieva ${ }^{6}$ afirmou que se a temperatura global continuar a subir ao ritmo que tem acontecido até agora pode implicar cortes entre $15 \%$ e $25 \%$ do Produto Interno Bruto (PIB) mundial.

Em termos de políticas ambientais é de referir que já em junho de 2009, o US Global Chamge Research Program (Programa Norte-Americano de Pesquisa sobre Mudança Climática) relatou observações que demonstram que o aquecimento do clima é inequívoco e que o aquecimento global observado nos últimos 50 anos é devido, sobretudo, à emissão de gases de efeito de estufa produzidos pela ação humana.

A síntese do Quinto Relatório de avaliação (Summary for Policymakers of the 5th Report) do IPCC dirigido aos decisores políticos, publicado em outubro de 2013, declarava já, então que: “O aquecimento do sistema climático é inquestionável. Desde a década de 1950, tem-se vindo a observar inúmeras mudanças sem precedentes nas últimas dezenas ou mesmo milhares de anos. A atmosfera e os oceanos aqueceram, a quantidade de neve e de gelo diminuiu, o nível médio das águas do mar subiu e a concentração de gases com efeito de estufa na atmosfera aumentou". Declarava, ainda, que: "A interferência antropogénica no sistema climático é indiscutível, sendo evidenciada pela crescente concentração de gases com efeito de estufa na atmosfera, pela força radioativa positiva, pelo aquecimento que se tem vindo a notar, bem como pela compreensão que temos do sistema climático. (...). É extremamente provável ${ }^{7}$ que a interferência antropogénica tenha sido a causa dominante do aquecimento a que se tem vindo a assistir desde meados do século XX. (...) As emissões contínuas de gases de efeito de estufa contribuirão para agravar este aquecimento e causarão alterações em todos os componentes do sistema climático. Para travar as alterações climáticas será necessário apostar numa redução substancial e progressiva das emissões de gases com efeito de estufa."

\footnotetext{
${ }^{6}$ Kristalina Georgieva é uma política búlgara e uma funcionária pública internacional. Foi diretora-geral do Banco Mundial entre 2017 e 2019 é a atual diretora-geral do Fundo Monetário Internacional. (fonte: Wikipédia). ${ }^{7}$ O termo "extremamente provável" diz respeito a uma probabilidade de ocorrência de 95\% a 100\%.
} 
Para evitar os cenários mais pessimistas a redução nas emissões deve ser significativa; algumas modificações importantes no Sistema Terrestre ${ }^{8}$ serão irreversíveis por muitos séculos, mesmo que as emissões cessassem agora; as decisões políticas tomadas nas próximas duas ou três décadas terão efeitos decisivos e de longo prazo, evitando, ou não, os denominados desastres naturais.

Mas, os desastres, denominados naturais, são muitas vezes mal interpretados pela maioria dos cidadãos - vistos apenas como fenómenos naturais ou, ainda, como consequências de castigos à humanidade, quando, na realidade correspondem ao resultado da interacção entre o mundo natural e os sistemas socioculturais, e tornam-se desastres quando afetam regiões e comunidades vulneráveis aos efeitos desta interacção, tanto em termos de vidas humanas, como de património arquitectónico, cultural e sistema económico. E, dependendo da magnitude do impacto poderemos passar de desastres a catástrofes. Podem ser o resultado de decisões, muitas vezes aparentemente desconectadas das consequências finais das mesmas, mas que afetam contextos sociais. Causadas por incapacidade ou falta de vontade em adotar padrões de vida sustentáveis.

Ora, para uma eficaz perceção da acção humana na mudança do clima é necessária uma visão do Planeta como sistema socioeconómico, cultural e político e parte integrante da captação de antecedentes e consequências de desastres, a qual, por sua vez, faz parte da construção de modelos descritivos e explicativos de perigos, riscos, vulnerabilidades, desastres e capacidade de lidar com os mesmos - resiliência. Tal envolve toda uma rede de atores, desde os cientistas aos decisores políticos para o esclarecimento de todos e sobretudo do grande público para que as percepções sobre a acção humana na mudança do clima, nomeadamente no aquecimento global, se reflicta não só em acordos ambientais, mas também em legislação global, com respectiva supervisão que penalize os responsáveis, seja por acção ou por omissão e, que leve, por sua vez, à co-responsabilização de todos e cada um enquanto seres do mesmo Planeta que almejam um desenvolvimento sustentável.

\section{Acordos Ambientais}

A preocupação com as questões ambientais tem sido objeto de diversos acordos internacionais nas últimas décadas. A Conferência de Estocolmo, realizada entre 5 e 16 de junho de 1972, foi a primeira Conferência das Nações Unidas sobre o Meio Ambiente Humano, realizada pela Organização das Nações Unidas (ONU). Representou o início das discussões internacionais sobre o Meio Ambiente.

A primeira discussão sobre a necessidade de proteção da camada de ozono ocorreu durante a Convenção de Viena, em 1985. O encontro serviu como base para o estabelecimento do entendimento internacional, sendo a base para o Protocolo de Montreal. Assinado em 1987, é um

\footnotetext{
${ }^{8}$ Sistema que compreende a atmosfera, a biosfera, a criosfera, a hidrosfera e a litosfera superior, a humanidade e todas as interações entre estas componentes.
}

Revista Ouricuri, Juazeiro, Bahia, v.11, n.1. p.080-102. jan./jul., 2021. 
acordo internacional, que ficou aberto para adesão dos países interessados. A principal meta do Protocolo de Montreal foi reduzir a emissão de gases $C F C^{9}$, responsáveis pela destruição da camada de ozono $^{10}$. Através do Protocolo de Montreal estimando-se que, entre 2050 e 2075, a camada de ozono sobre a Antártica retorne aos níveis da década de 80 do sécilo XX. Outro objetivo é o de reduzir de 1,1 milhão de toneladas para 70 mil toneladas o consumo de CFCs em todo 0 mundo. A redução das emissões de gases CFC também representa a redução de mais de 2 milhões de casos de cancro de pele em pessoas de todo o mundo. A Rio-92 ocorreu após 20 anos da Conferência de Estocolmo. Também chamada de Conferência das Nações Unidas sobre o Meio Ambiente e Desenvolvimento, ocorreu no Rio de Janeiro, em 1992. Na ocasião, 172 países reuniram-se para avaliar os principais problemas ambientais e discutir metas de redução dos impactos por eles gerados. Como resultado surgiu a Agenda 21, que envolvia a dimensão social, económica, cultural, educacional e ambiental das populações. O objetivo era conduzir ao desenvolvimento sustentável como forma de melhorar a qualidade de vida das pessoas e do meio ambiente.

Em 1997 é assinado o Protocolo de Kyoto, no Japão, um tratado internacional, cujo objetivo era alertar para o aumento da concentração dos gases efeito de estufa e do aquecimento global. Teve importância por ser o primeiro acordo a estabelecer metas de redução de gases efeito de estufa. O Protocolo de Kyoto só entrou em vigor, a partir de 2005, durante a COP 11, em Montreal. A Rio + 10 ocorreu entre 26 de agosto e 4 de setembro de 2002, em Joanesburgo, na África do Sul. O objetivo do encontro era avaliar os avanços dos acordos definidos na Rio-92. O evento serviu também para reforçar a necessidade e urgência de atender o que foi acordado durante a Rio-92. A COP 15 (Conferência das Partes sobre o Clima) foi realizada pela Convenção-Quadro das Nações Unidas sobre Mudança do Clima, nos dias 7 a 18 de dezembro de 2009, em Copenhague, na Dinamarca. O objetivo do encontro era discutir as alternativas para enfrentar o aquecimento global. O cenário apontado pelos cientistas é de que a temperatura da Terra não poderia aumentar mais do que $2{ }^{\circ} \mathrm{C}$ em relação aos níveis pré-industriais, até o final do século. Caso contrário, poderia alcançar-se um ponto irreversível das mudanças climáticas.

Antes, mesmo, das negociações que ocorreriam durante o COP-15 em Copenhaga em dezembro de 2009, as academias nacionais de ciência das nações G8+5 publicaram uma Declaração Conjunta dizendo que "a mudança climática e o uso de fontes de energia renováveis são desafios cruciais para o futuro da humanidade. Foi enfatizada a necessidade dos líderes mundiais concordarem sobre a redução de emissões, necessária para combater as consequências

\footnotetext{
${ }^{9} \mathrm{O}$ clorofluorcarboneto (ou clorofluorcarbono ou CFC) é um composto com base em carbono e que contém cloro e flúor, responsável pela redução da camada de ozono, e já, em tempos, usado como aerossóis e gases para refrigeração, sendo actualmente proibido o seu uso em vários países, no âmbito do Protocolo de Montreal.

${ }^{10}$ A camada de ozono corresponde a uma cobertura gasosa que envolve e protege a Terra da radiação ultravioleta emitida pelos raios solares. Os buracos na camada de ozono formam-se quando a concentração deste gás cai abaixo de $50 \%$ e são formados através da libertação de gases CFC na atmosfera, com efeitos principalmente na Antártida.
} 
negativas da mudança climática antropogénica". A declaração cita o Quarto Relatório do IPCC de 2007, e afirma que "a mudança climática está a ocorrer ainda mais rapidamente do que era estimado; as emissões globais de CO2 desde 2000 foram mais altas do que mesmo as mais altas previsões, o gelo do Ártico tem derretido de forma muito mais rápida do que era projetado, e a subida do nível do mar tornou-se mais rápida".

A Rio + 20, também chamada de Conferência das Nações Unidas sobre o Desenvolvimento Sustentável, ocorreu entre os dias 13 e 22 de junho de 2012, no Rio de Janeiro. Foi um dos maiores eventos já realizados pela ONU e contou com a participação de mais de 180 países. Teve como objetivo fortalecer e assegurar o desenvolvimento sustentável entre os países envolvidos. Um tema bastante discutido foi a Economia Verde, que significa o crescimento económico aliado à redução da emissão de gases poluentes. Por sua vez, o Acordo de Paris é o último compromisso internacional discutido entre 195 países com o objetivo de minimizar as consequências do aquecimento global. Foi adotado durante a Conferência das Partes - COP 21, em Paris, no ano de 2015. Tem como objetivo fortalecer a resposta global à ameaça das mudanças climáticas. Foi aprovado pelos 195 países participantes que se comprometeram a reduzir emissões de gases efeito de estufa. O objetivo é o de manter a temperatura média da Terra abaixo de $2^{\circ} \mathrm{C}$, acima dos níveis pré-industriais. Além de esforços para limitar o aumento da temperatura até $1,5^{\circ} \mathrm{C}$ (acima dos níveis pré-industriais), os países desenvolvidos também se comprometeram a conceder benefícios financeiros aos países mais pobres, de modo que possam enfrentar as mudanças climáticas.

Naturalmente, os acordos internacionais acima mencionados têm que ser complementados com mudanças de paradigma político, jurídico e de estratégias holistas, na perspectiva de que o Planeta é comum e, portanto, a responsabilidade dos países tem que ser proporcional à sua riqueza e ao seu grau de impacto negativo nas alterações climáticas, tendo em conta que há opções para a mudança e que essa mudança deve ser acompanhada da proteção do trabalho e, portanto de requalificações e adaptações nas formas de trabalho, enquadradas em novos modelos económicos.

Em Davos (2018), Georgieva afirmava que a luta contra alterações climáticas terá que ter em conta que milhares de empregos poderão ser destruídos, ligados a setores condenados a desaparecer, como por exemplos os ligados aos combustíveis fósseis, portanto há que ter em conta a reconversão da economia e dos trabalhadores para os setores emergentes. Apostar na na reconversão de indústrias poluentes em indústrias verdes, energias renováveis, fazendo desaparecer setores como o do carvão, sem esquecer a reconversão, a formação e a educação estas têm que ser as apostas do novo paradigma de desenvolvimento social.

O investimento em novas tecnologias não pode fazer desaparecer postos de trabalho, deve promover o surgimento de outros, novos, postos de trabalho, inclusivos de todos os cidadãos. $\mathrm{E}$ neste aspeto é que os governos poderão entrar em choque com interesses de organizações empresariais, cujo destino será desaparecerem ou reconverterem-se. As pessoas são necessárias a esta transição, no desempenho do trabalho e consequente avanço económico. É necessário 
adotar medidas políticas adequadas com incentivos à inovação e proteção do trabalho e rendimentos dos cidadãos, e, assim, proteger a sua qualidade de vida, com regulamentação, medidas e fiscalização, que se estendem ao comportamento individual.

Será, portanto, no âmbito de uma mudança de paradigma económico e político, não hegemónico, que a mudança no respeito pelas comunidades e cidadãos resilientes deverá ser pensada.

\section{O NEGACIONISMO CLIMÁTICO}

Mas, apesar do esmagador consenso científico e de outros atores institucionais em torno do aquecimento global, decorrente da acção humana, existem vozes politicamente influentes que negam a acção antrópica no aquecimento do Planeta. O negacionismo ocorre em muitos países, mas especialmente nos Estados Unidos e no Reino Unido, onde é promovido por um pequeno mas poderoso lobby, estratégica e principalmente organizado pela indústria dos combustíveis fósseis. As principais razões para o pensamento negacionista, que se opõe ao consenso científico sobre o aquecimento global, assentam nos pressupostos de que o combate ao aquecimento e a mudança para um modelo sustentável ou serão custosos demais ou ineficazes, ou que de alguma forma ameaçam a liberdade, a soberania das nações, a propriedade privada, o livre mercado ou a acumulação de capital. O negacionismo climático tem sido considerado uma grave ameaça ao bem comum e ao futuro das gerações e tem sido extensivamente associado a grupos conservadores e ultraconservadores, ideologias fundamentalistas, preconceitos de classe, desonestidade intelectual e atividades criminais ou obscuras.

Por exemplo, numa carta de investigadores da UP, em 2018, acerca de uma controversa reunião de negacionistas, que teve lugar naquele ano na Faculdade de Letras da Universidade do Porto, Portugal, já antecipando uma eventual reação a esta carta, em nome da liberdade e/ou invocando censura, os signatários antecipam-se: "Não somos alheios às táticas frequentemente utilizadas por este tipo de organizações negacionistas, que utilizam o espaço da democracia para tentar polarizar a sociedade e ganhar espaço mediático, criando uma polémica artificial e errada, invocando censura e vitimizando-se no processo". "Sendo uma universidade pública e uma das maiores produtoras de Ciência em Portugal, à Universidade do Porto impõe-se o escrutínio dos eventos que acolhe", referem ainda, concluindo que a instituição "pela responsabilidade que tem em divulgar o conhecimento informado, não deve emprestar o nome e dar credibilidade à negação da Ciência e do Conhecimento".

O negacionismo em vez de esclarecer sobre o impacto humano nas alterações climáticas gera dúvidas até sobre o próprio método científico que deve trabalhar continuadamente, mesmo com incerteza, até que a acumulação de factos constituam prova necessária e suficiente para produzir análises e conclusões. E desta forma contribui para a sedimentação de percepções dissonantes da evidência factual. 
E, quando a ciência não é suficiente, importa associar o cidadão comum aos debates e decisões que costumam ser apenas para especialistas tem vindo a receber grande consideração em muitos países como forma de distribuir responsabilidades em decisões como as que envolvem consequências indesejáveis para o ambiente, saúde e segurança públicas, mas também como forma de mobilizar diferentes formas de conhecimento, contribuindo, assim, para um mais abrangente, mais detalhado e melhor acesso e identificação dos medos e incertezas específicas, associadas a riscos específicos, através da reconstrução de diversificadas configurações que associam o cidadão comum e especialistas, em contextos específicos (Irwin and Wynne, 1996).

As emergentes configurações que associam o cidadão comum e especialistas são, neste sentido, uma pré-condição para iniciativas participadas nos processos de identificação e gestão dos riscos, incluindo diferentes tipos e sistemas de aviso prévio, os quais requerem a participação e cooperação, contextualmente situada, de um largo espectro de diferentes actores, sejam eles cidadãos comuns, ou especialistas (Callon et al., 2001); Chateauraynaud and Torny, 1999).

Estas configurações implicam processos e estratégias de comunicação entre diferentes mundos sociais. E, quando nos referimos a comunicação entre diferentes mundos sociais que pressupõem processos de apreensão do real estamos a remeter para formas de disseminação e interiorização de imagens e conteúdos, significante e significados, que consolidam as representações sociais sobre os conteúdos comunicados, as quais permitem uma leitura, ou perceção, do real, que remetem para visões do mundo. Uma representação sem conteúdo é um oxímoro, e as formas que os processos de comunicação assumem nos diferentes grupos constrangem os conteúdos das representações; o seu conteúdo é, assim, funcional em função dos diversos meios sociais nos quais são privilegiadas formas particulares de ancoragem e objectivação (Jesuíno, 2001). As funções das representações; organizam o real de forma significante; desempenham uma função de explicação e argumentação; contribuem para a diferenciação social respondendo à procura de identidade positiva dos grupos; e têm um papel na organização dos comportamentos, intenções e ações comunicacionais (Abric \& Guimelli, 1998; Farr, 1993).

\section{CONDUZIR AO DESENVOLVIMENTO SUSTENTÁVEL}

No decurso da história da humanidade, os riscos sempre estiveram presentes. Contudo, são hoje de natureza qualitativamente diferente. Ao risco confere-se, atualmente, o mesmo grau de importância que obteve a pobreza no século XIX, e a segurança no século XX. Desde então, a confiança e a legitimidade políticas são conseguidas através do progressivo desenvolvimento do Estado Providência, assente nos pressupostos do controle e da segurança, através dos quais tanto as instituições públicas como privadas providenciam garantias contra o risco em diversas dimensões da vida, nomeadamente na saúde pública, pensões, subsídios de desemprego e de doença e benefícios de bem-estar. E, o facto de as pessoas estarem expostas a perigos (em relação aos quais não têm capacidade de decisão) é, em alguma extensão, dependente do conhecimento, 
um conhecimento que frequentemente as vítimas não possuem para poderem decidir sobre eventuais riscos aceitáveis (Luhmann, 1993). As teorias sociais sobre as denominadas sociedades de risco recordam-nos que as sociedades modernas se encontram confrontadas com os limites do próprio modelo de desenvolvimento. Sendo que o progresso na via do desenvolvimento sustentável torna-se mais exigente em tempos de turbulência, crises e incerteza.

A Universidade das Nações Unidas estabeleceu em 1973 o Instituto para a Segurança Humana e do Ambiente (UNU-EHS, da sigla em inglês) para abordar riscos e vulnerabilidades, consequências de riscos ambientais complexos, agudos e latentes. Evitando que o conceito de desenvolvimento sustentável se tornasse mais um princípio adjetivo do que um conceito estrutural; a UNU-EHS desenvolveu investigação e metodologias de avaliação de vulnerabilidades associadas a diferentes riscos, decorrentes de impactos tanto de fenómenos naturais, quanto da ação humana. Pois, as condições dos sistemas homem-ambiente e contextos sócio económicos e de conhecimento determinam a sua sensibilidade a qualquer conjunto de exposições danosas. Por sua vez, a incorporação das diferenças na resiliência dos diferentes contextos sociais tornou-se um elemento crucial da análise dos sistemas homem-ambiente. E, as qualidades sistémicas homemambiente-contextos sociais estão abertas a constantes reformulações em função do avanço do conhecimento sobre as consequências do impacto e incremento de fenómenos naturais decorrentes da ação humana; dependendo dos interesses e objetivos de quem as usa.

Segundo a UNU-ERHS, no sentido de preservar a segurança humana, as principais prioridades de um programa a tal dedicado, deverá ter em consideração: (i) avaliação de vulnerabilidades, análise de resiliência, gestão de risco e estratégias de adaptação no âmbito da interligação dos sistemas homem-ambiente; (ii) deslocamento interno e migração transfronteiriça devidas as fatores que afetam as mudanças climáticas; (iii) Preparação, adaptação, resposta e recuperação. Neste enquadramento, a resiliência emerge como um conceito operacional com potencial para promover trajetórias mais sustentáveis para os processos políticos e de planeamento. Pois a resiliência reflete a capacidade de um sistema (uma região, uma atividade económica, uma cidade, um lar) absorver perturbações e se reorganizar sem colapsar ou mudar consideravelmente a sua identidade, evitando, assim, perder as suas características principais; importando, portanto, avaliar o potencial de resiliência de um sistema para desempenhar um papel fundamental, nomeadamente quando crises, instabilidade, incerteza e complexidade constituem fatores interligados na caracterização de um contexto social e consequentes impactos no homem.

A caracterização do impacto social das alterações climáticas em termos de uma adaptação sistémica (interação do homem-ambiente-contexto social) (Latour, 2017; 2018) exige algumas ações e recomendações fundamentais a serem usadas para avaliar, formular e criar planos políticos, simultaneamente, nacionais e internacionais que assegurem o desenvolvimento 
sustentável das nossas sociedades de risco e de modernização reflexiva, onde todos somos chamados à co-responsabilização nas decisões ${ }^{11}$.

\section{MODERNIZAÇÃO REFLEXIVA}

No atual período de modernização reflexiva caracterizado por perigos a uma escala sem precedentes e incalculáveis, que expõem a inadequação do sistema providência; a segurança é, agora, apresentada como outro bem de consumo, parte do progresso material da sociedade. Tornase evidente a necessária emergência de diversos sistemas de segurança, no sentido de que a sociedade como um todo comece a ser percebida, em termos de insegurança, como um grupo de risco, em que o Estado Providência seja um Estado que providencia. Por esta razão, no mundo das sociedades de risco, tanto a qualidade de vida, como a produção de conhecimento não podem estar conjunta e mutuamente fechadas, na defesa de medidas de prevenção, que passam por regras de regulamentação e fiscalização, pela necessidade de intervenção dos Estados. O cientista, enquanto cidadão manifesta um sentimento de grande proximidade com o público leigo, na partilha do mesmo tipo de preocupações. Esta partilha está ancorada no movimento que ocorreu na comunidade científica, no sentido de um maior investimento na prevenção. No papel de expert o cientista representa quem se consulta numa lógica factual; no papel de cidadão, o cientista é um indivíduo preocupado em contribuir para influenciar decisões, pondo o seu conhecimento ao serviço da sociedade, numa perspetiva de solidariedade com responsabilidade social (Diego Gonçalves, 2006).

Este emergente Paradigma da Responsabilização é, ainda, da Solidariedade, mas requerendo, agora, mais democracia - a produção de accountability, redistribuição do ónus da prova, divisão dos poderes entre os produtores e os avaliadores dos perigos e disputas públicas sobre alternativas. Emerge a necessidade de que seja criado um espaço público de discussão e de resposta contra os perigos e a falsa segurança de uma 'sociedade concebida em abstrato'. A credibilidade, aceitabilidade, e a confiança assentam num processo de criação de coligações discursivas baseada numa definição partilhada da realidade. O Paradigma da Responsabilização deve ser enquadrado no âmbito de uma abordagem estruturada para análise do risco; avaliação, gestão e comunicação do risco, o que implica a mobilização ou a recomposição de redes e atores transnacionais, a um tempo científicas e sociais, requerendo a institucionalização do movimento ambiental/ecológico onde se incluem os impactos do fenómeno climático. O ecológico é político.

Perspetiva esta que não deixa de fora a problemática das culturas epistémicas e arenas de negociação, assim como os processos de "tradução", nem tão pouco a proposta de "trading zone"

\footnotetext{
11 Veja-se: https://casacomum.pt/2018/07/21/casa-comum-da-humanidade.tem-sede-no-porto/ sobre o projecto: "Common House of Humanity". E, para uma melhor compreensão cf., ainda, Bertolami and Francisco (2018a;b). De interesse, ainda ver Latour $(2017 ; 2018)$ sobre os sistemas homem-sociedade, a dicotomia natureza/cultura, bem como as "zonas de comércio", num mundo de incontáveis transações de seres agindo incessantemente uns sobre os outros.
}

Revista Ouricuri, Juazeiro, Bahia, v.11, n.1. p.080-102. jan./jul., 2021. 
para explicar as trocas sociais e intelectuais que se efetuam entre tradições culturais, sejam teóricas, experimentais ou técnicas, desenvolvendo desta forma trabalho conjunto em "zonas de negociação", que podem dialogar com outras formas de conhecimento e mundos sociais, aprofundando e multiplicando a comunicação entre dinâmicas específicas dos diferentes mundos sociais, ancoradas em estratégias de comunicação (Jesuíno e Diego, 2003) que pressupõem processos de apreensão de mensagens, através das quais se "uniformiza" o risco socialmente aceitável, função de decisões políticas, ou considerado enquanto tal, mas que também permitirá, através do conhecimento que providencia, escolhas sociais e individuais diferenciadas.

\section{CONCLUSÕES}

Em síntese, podemos afirmar que as implicações nas mudanças climáticas e impacto no ecossistema terrestre causadas pelo homem acontecem a uma escala de grandeza sem precedentes desviando-nos das condições de referência do Holoceno, colocando-nos numa emergente época geológica. Este é um problema de natureza multidimensional, não se reduzindo aos clássicos termos geológicos - unidades de tempo e de estratos. As sociedades desenvolveramse e os processos civilizacionais cresceram e decaíram, no decurso dos milénios que se inscrevem no Holoceno, sem alterar significativamente o caráter fundamental do sistema terrestre. Paradoxalmente é a própria agudeza das mudanças recentes que torna funcional o Antropoceno como unidade geológica. Mas o que causou esse extraordinário aumento que está a transformar a geologia do Planeta? A resposta está claramente num ponto de intersecção de dimensões éticas, políticas, económica, desenvolvimento tecnológico, mudança social, tendo como fator primordial a forma como a ação humana promove riscos a uma escala cada vez maior, nomeadamente por via da evolução cada vez mais rápida da tecnologia ao ponto em que se sugeriu que essa resposta reside no coração da "tecnosfera", um novo sistema terrestre, com a sua própria dinâmica (e com os seres humanos mais como componentes do que como propulsores), que brotou - e que agora, talvez se possa dizer que parasita - da biosfera.

No sentido de promover a sustentabilidade das sociedades humanas, dependendo fortemente do ambiente, o desenvolvimento da interdisciplinaridade científica é muito importante para assegurar uma melhor compreensão do nosso ambiente vivo, seu equilíbrio e até das suas mudanças e capacidades humanas de adaptação.

O objetivo da interdisciplinaridade que propomos para a investigação e comunicação científica nesta área é o de encontrar a multiplicidade de fatores e descobrir como e porque são agora os homens os principais causadores da mudança geológica na Terra, propondo, também, meios de controlar o seu impacto, tendo em conta que as condições de emergência e consolidação desta nova era geológica - o Antropoceno - em evolução afetarão todas as nossas vidas por muitas gerações no futuro. Importa, portanto perceber o alcance dos pressupostos em que estão ancorados 
os discursos epistemológicos que descrevem o modo como o Antropoceno emergiu dos longos e estáveis milénios do Holoceno - inicialmente devagar durante a Revolução Industrial, e de forma mais rápida durante a Grande Aceleração, que ainda continua.

Também importante se torna o uso da moderna tecnologia científica na construção de modelos científicos com aplicabilidade prática, quanto na divulgação científica contribuindo para a literacia científica dos cidadãos; promovendo escolas de aprendizagem internacionais no âmbito de planos de comunicação com a sociedade.

Em suma, com melhores performances científicas parece possível desenvolver melhores diagnósticos, e também planos de educação e comunicação com diversos gabinetes públicos, políticos e a população em geral, no sentido de se obter uma melhor rede nacional e internacional de informação acerca de acontecimentos que, ainda que locais, são multicausais, e têm consequências transnacionais.

AGRADECIMENTOS: Agradecemos a Josilda Lima Xavier, da UNEB, o interesse e sugestão na publicação deste trabalho, bem como o cuidado e tempo que dedicou à revisão do texto.

\section{REFERÊNCIAS}

Abric, J.C. ; Guimelli, C. Représentations socials et effets de contexte. Connexions. 72, 2, 23-38, 1998.

Barbosa, M.; Bertolami, O.; Francisco, F. Towards a Physically Motivated Planetary Accounting $\begin{array}{llll}\text { Framework. The } & \text { Anthropocene }\end{array}$ Doi: https://doi.org/10.11772053019620909659.

Beck, U. World Risk Society. Cambridge: Polity Press, 1999.

Beck, U. Risk Society. Towards a New Modernity. Tr. Mark Ritter. London: Thousand Oaks, New Delhi, Sage Publications ( $1^{\text {st }}$ ed. 1986), 1992.

Beck, U.; Giddens, A. and Lash, S. Reflexive Modernization. Politics. Tradition and Aesthetics in the Modern Social Order. Cambridge, UK: Polity Press. (1 ${ }^{\text {st }}$ ed. 1994), 1977.

Bertolami, U. Utopia: Utopian and Scientific, (http://web.ist.utl.pt/orfeu.bertolami/Bertolami_Utopia_2018.pdf). 2018b.

Bertolami, O. A Humanidade no Antropoceno.

(https://forumdemosnet.wordpress.com/2018/12/01/a-humanidade-no-antropoceno/). 2018a.

Bertolami, O.; Francisco, F. Alterações climáticas e o Sistema Terrestre. Rev. Ciência Elementar, v. 8(4):051. DOI: http://doi.org/10.24927/rce2020.051. 2021b.

Bertolami, O. and Francisco, F. A digital contract for the restoration of the Earth System mediated by a Planetary Boundary Exchange Unit. The Anthropocene Review. DOI: 10.1177/2053019620987270. 2021a. 
Bertolami, O.; Francisco, F. A Physical Framework for the Earth System in the Anthropocene: Towards an Accountancy System. In: ATAS DO ENCONTRO IBEROAMERICANO DE ESTUDOS DO ANTROPOCENO, September. 2019. https://arxiv.org/pdf/1910.02467.pdf.

A physical framework for the earth system, Anthropocene equation and the great acceleration. Global Planet Change, 169. 2018b. p. 66-69. DOI: 10.1016/j.gloplacha.2018.07.006.

Using Physics to Capture the Changes to the Earth System in the Antropocene. 2018a. (https://sciencetrends.com/using-physics-to-capture-the-changes-to-the-earth-system-in-theanthropocene/).

Callon, M.; Lascoumes, P.; Barthe, J. Agir dans un monde incertain. Essai sur la Démocratie Technique. Paris : Seuil, 2001.

Chateauraynaud, F.; Torny, D. Les Sombres Précurseurs. Une sociologie pragmatique de l'alerte et du risqué. Paris: Éditions de l'École des Hautes Études en Sciences Sociales, 1999.

Diego Gonçalves, C. The importance of Social Capital Facing the Unexpected (From Natural Hazards to Social Disasters) - A Style of Thought. In: Isabel CAPELOA GIL, Isabel and WULF, Christoph (Org.). Hazardous Future. De Gruyter, 2015. p. 79-94.

Desastres Naturais. Algumas Considerações: Vulnerabilidade, Risco e Resiliência. Territorium - Associação RISCOS, 19. 2012. p. 5-14.

Incerteza, gestão e decisão: o caso do risco sísmico. In: ATAS DOS ATLIERS DO V CONGRESSO PORTUGUÊS DE SOCIOLOGIA. Sociedades Contemporâneas: Reflexividade e Ação. Atelier: Modernidade, Incerteza e Risco. 2014.

Diego, C. (Re)pensar a ciência como cultura. Sociologia, Problemas e Práticas, n. 2. Lisboa: CIESISCTE. 1996b. p. 4-68.

Diego, C. O Papel Cultural do Cientista nas Sociedades Pós-Industriais. In: Gonçalves, Maria Eduarda (Coord.). Ciência e Democracia. Lisboa: FEPASC, Bertrand Editora, 1996a.

Farr, R. Common sense, science and social representations. Public Understanding of Science, 2. 1993. p. 189-205.

Giddens, A. As Consequências da Modernidade. Oeiras: Celta, 1992.

1991.

Modernity and Self-Identity: self and society in the late modern age. Cambridge: Polity Press,

Gonçalves, C. and Bertolami, O. Anthropic risks, coronavirus pandemic (COVID-19), climate change (\& other disasters): An attempt to reach public perception.2020b.

Available at: https://papers.ssrn.com/sol3/papers.cfm?abstract_id=3703878.

Pandemias, riscos, crises: a importância de investir em comunidades resilientes.

Sociedades que potenciam o risco, populações que sofrem sem que tenham uma palavra a dizer". Opinião. In Jornal Público, online, 8 de Junho, Portugal. 2020a.

(https://independent.academia.edu/CarmenDiegoGonçalves).

Graedel, T. and Crutzen, P. Atmosphere, Climate, and Change. New York: Scientific American Library, 1995.

Irwin, A. \& Wynne, B. (Org.) Misunderstanding science? The Public Reconstruc-tion of Science and Technology, Cambridge: Cambridge University Press, 1996. 
Jesuíno, J. C. Ancrages. Tensions épistémiques. In : FABRICE BUSCHINI et NIKOS KALAMPALIKIS (Ed.), Penser la vie, le social. La nature. Mélanges en l'honneur de Serge Moscovivi. Paris: Éditions de la Maison des sciences de l'homme, 2001. p. 277-291.

Jesuíno, J. C. e Diego, C. Estratégias de comunicação dos cientistas. In: Gonçalves, Maria Eduarda (Org.). Os Portugueses e a Ciência. Lisboa: Bertrand, 2003.

Jodelet, D. À la recherche de la mémoire. In : BUSCHINI, Fabrice et KALAMPALIKIS, Nikos (ed.). Penser la vie, le social. La nature. Mélanges en l'honneur de Serge Moscovivi. Paris: Éditions de la Maison des sciences de l'homme, 2001. p. 467-481.

Lash, S. Risk Culture. In ADAM, Barbara; BECK, Ulrick and VAN LOON, Joost (Eds.), Positioning Risk. London: Sage, 2000.

Latour, B. Down to Earth, Politics in the New Climate Regime. Cambridge: Polity Press, 2018.

Latour, B. Facing Gaia. Eight lectures on the new climatic regime. Cambridge: Polity Press, 2017.

Luhmann, N. Risk: A Sociological Theory. Berlin: New York, Walter de Gruyter, 1993.

Merton, R. La sociología de la ciencia, 1. Investigaciones teóricas y empíricas. Madrid: Alianza Editorial. (ed. orig. 1973). 1985.

Moscovici, S. et Hewstone, M. De la science au sens commun. In : MOSCOVICI, Serge (Ed.). Psycologie Sociale. Paris : PUF, 1984. p. 539-566.

Steffen, W.; Rockström, J.; Richardson, K.; Lenton, T.; Folke, C.; Liverman, D.; Summerhayes, C.; Barnosky, A.; Cornell, S.; Crucifix, M.; Donges, J.; Fetzer, I.; Lade, S.; Scheffer, M.; Winkelmann, R. and Schellhuber, H. J. Trajectories of the Earth System in the Anthropocene. In: WILLIAM Clark (Ed.). Cambridge: Harvard University. PNAS, August 14, 115 (33). 2018, p. 8252-

8259. (https://doi.org/10.1073/pnas.1810141115).

Slovic, P. The Perception of Risk. London and Sterling: Earthscan Publications, 2000.

Wynne, B. May the sheep safely graze? A reflexive view of the expert-lay knowl-edge divide. In: LASH, Scott; Bronislaw. SZERSZYNSKI; WYNNE, Brian (Orgs.). Risk, Environment and Moder-nity: towards a new ecology. Londres: Sage, 1996. 